\title{
Impact of Processing Parameters in Plasma Electrolytic Oxidation (PEM) on Corrosion Resistance of Magnesium Alloy Type AZ91
}

\author{
Talal Aljohani ${ }^{1}$, Sami Aljadaan ${ }^{1}$, Meteb Bin Rubayan $^{1}$, and Fuad Khoshnaw ${ }^{2}$ \\ ${ }^{1} \mathrm{KACST}$ \\ ${ }^{2}$ De Montfort University
}

April 8, 2021

\begin{abstract}
This study aims to investigate the effect of the processing parameters in plasma electrolytic oxidation (PEO) on the corrosion resistance of magnesium alloy type AZ91. The PEO coatings were prepared on the samples using alkaline-based electrolyte. Both unipolar and bipolar, different frequencies and duty cycles were applied. Corrosion tests, using potentiodynamic polarisation (PDP), linear and cyclic, and electrochemical impedance spectroscopy (EIS) techniques, were applied on the as-received and PEO coated samples. Scanning electron microscopy was used to investigate the surface morphology, e.g. micropores, as well as to measure the thickness of the coated layer with changing the processing parameters. The results show that the size of micropores is interrelated to the duty cycle percentage and current polarities, as the higher frequency causes thinner coating layers, with fewer micropores, consequently higher corrosion resistance. In addition, increasing the duty cycle, a denser and more compact coating was obtained. The XRD results showed missing peak of the $\alpha$-Mg phase in a PEO coated sample using Bipolar, the highest frequency $(1666 \mathrm{~Hz})$ and the highest duty cycle $(66.6 \%)$. The mils per year calculations showed that the PEO coated have lower corrosion rate by at least 8 times than the as-received alloy.
\end{abstract}

\section{Hosted file}

manuscript.pdf available at https://authorea.com/users/406618/articles/517200-impact-ofprocessing-parameters-in-plasma-electrolytic-oxidation-pem-on-corrosion-resistance-ofmagnesium-alloy-type-az91

\section{Hosted file}

Figures.pdf available at https://authorea.com/users/406618/articles/517200-impact-ofprocessing-parameters-in-plasma-electrolytic-oxidation-pem-on-corrosion-resistanceof-magnesium-alloy-type-az91 